\title{
Histological Disorganization of Spleen Compartments and Severe Visceral Leishmaniasis
}

\author{
Micely d'El-Rei Hermida, Caroline Vilas Boas de Melo, Isadora dos Santos Lima, \\ Geraldo Gileno de Sá Oliveira and Washington L. C. dos-Santos*
}

Fundação Oswaldo Cruz, Instituto Gonçalo Moniz, Salvador, Brazil

The spleen is a secondary lymphoid organ responsible for immune surveillance against blood-circulating pathogens. Absence of the spleen is associated with increased susceptibility to systemic spread and fatal infection by different pathogens. Severe forms of visceral leishmaniasis are associated with disorganization of spleen compartments where cell interactions essential for splenic immunological function take place. White pulp atrophies, secondary lymphoid follicles and marginal zones vanish, and the boundaries separating white and red pulp blur. Leukocyte populations are reduced or disappear or are replaced by plasma cells. In this paper, we review the published data on spleen

OPEN ACCESS

Edited by:

Javier Moreno,

Instituto de Salud Carlos III, Spain

Reviewed by:

Yang Zhang,

University of Pennsylvania,

United States

Carla Maia

Universidade NOVA de Lisboa

Portugal

${ }^{*}$ Correspondence:

Washington L. C. dos-Santos

wluis@bahia.fiocruz.br

Specialty section:

This article was submitted to

Parasite and Host,

a section of the journa

Frontiers in Cellular and Infection

Microbiology

Received: 14 June 2018

Accepted: 19 October 2018

Published: 13 November 2018

Citation:

Hermida M-R, de Melo CVB, Lima IdS, Oliveira GGdS and dos-Santos WLC (2018) Histological Disorganization of Spleen Compartments and Severe Visceral Leishmaniasis.

Front. Cell. Infect. Microbiol. 8:394. doi: 10.3389/fcimb.2018.00394 disorganization in severe forms of visceral leishmaniasis and propose a histological classification to help the exchange of information among research groups.

Keywords: visceral leishmaniasis, white pulp disruption, spleen disorganization, Leishmania infantum, spleen pathology

\section{INTRODUCTION}

Visceral leishmaniasis (VL) is a severe parasitic disease caused by infection by Leishmania infantum (syn. Leishmania chagasi) or Leishmania donovani that affects both humans and dogs. Visceral leishmaniasis is distributed in Central and South America, Asia, parts of Africa and the Mediterranean basin, with an estimated burden of 2.1 million DALY (disability adjusted life years) (Townson et al., 2005). The infection may be silent or present with slight clinical manifestations (Badaró et al., 1986). However, some patients progress to a clear pattern of clinical disease with weight loss, hepatomegaly, splenomegaly, anemia, thrombocytopenia and leukopenia, including neutropenia, and increased susceptibility to bleeding and coinfections (Badaró et al., 1986; Costa et al., 2010). The current therapeutic regimes with antimonials or with amphotericin are effective in most of the cases of VL (Herwaldt, 1999). However, the disease maintains an approximately 7\% lethality in Brazil, even among patients under treatment (Ministério da Saúde do Brasil, 2010).

The spleen, bone marrow, and liver are the main organs involved in VL. The spleen is affected in all cases of the disease. Furthermore, while some control of infection is observed in the liver, the infection acquires a progressive character in the spleen throughout the course of the disease (Wilson and Streit, 1996; Carrión et al., 2006), leading to disruption of white pulp (WP) structure and replacement of normal cellularity of the red pulp (RP) by plasma cells (Silva-O'Hare et al., 2016). Such structural disorganization of the spleen is associated with severe forms of VL (Veress et al., 1977; Lima et al., 2014). In this work, we review the published data on spleen disorganization in VL and the pathways involved in the process. Our aim is to draw attention to the spleen as a potential source of biological markers for identifying patients susceptible to progress to severe forms of VL. Early identification of these patients may contribute for designing more effective therapeutic strategies for progressive forms of the disease. 


\section{THE NORMAL SPLEEN}

The spleen is a large secondary lymphoid organ composed of two compartments: the RP and the WP, and present morphological variation among different species (Figure 1; Steiniger and Barth, 2000; Cesta, 2006). Cords, sinuses and blood vessels mainly comprise the RP, which contains lymphocytes macrophages, erythrocytes and a small number of plasma cells. The splenic RP perform hemocateresis and keeps strict control of iron stores, reducing their availability to circulating pathogens (Mebius and Kraal, 2005). The process involves the SLC11/Nramp (natural resistance-associated macrophage protein) family whose polymorphism is associated with susceptibility to a variety of pathogens (Wessling-Resnick, 2015). The spleen is the site of differentiation and homing of inflammatory macrophages, monocytes, granulocytes, dendritic cells, natural killer cells and short-lived plasma cells (Ellyard et al., 2005; Mebius and Kraal, 2005). In the WP, take place T- and B-cell differentiation and immune responses to blood-borne antigens (Mebius and Kraal, 2005). The WP is constituted by three regions: the periarteriolar lymphocyte sheath (PALS), lymphoid follicles and marginal zones (MZ). Layers of predominantly $\mathrm{CD}^{+} \mathrm{T}$ lymphocytes surrounding segments of small arteries forms the PALS. Contiguous with the PALS, the lymphoid follicles emerge as sparse round aggregates of predominantly B lymphocytes. There is always a variety in the primary and secondary lymphoid follicles. Primary lymphoid follicles are small nodular aggregates of small lymphocytes (Beyer and Meyer-Hermann, 2008). Secondary lymphoid follicles are large lymphoid aggregates that present germinal centers (GC). Germinal centers are composed of large proliferating lymphocytes, large macrophages sometimes containing apoptotic bodies, some follicular dendritic cells and some T lymphocytes (MacLennan, 1994). A ring of small lymphocytes (mantle zone) surrounds the follicle GC (Brozman, 1985). A diffuse layer containing predominantly B lymphocytes, some $\mathrm{T}$ lymphocytes and various macrophage populations form the MZ, which is more evident around the lymphoid follicles. The splenic MZ is the homing site for memory $\mathrm{B}$ cells responsive to T-lymphocyte dependent and T-lymphocyte independent response antigens (Kraal, 1992; Lopes-Carvalho et al., 2005).

The maintenance and organization of splenic compartments are controlled by a complex signaling network of chemokines (mostly of CC and CXC family), cytokines and adhesion molecules (den Haan et al., 2012). Lymphoid follicle architecture is dependent on CXCL13 secretion by stromal and follicular dendritic cells (Shi et al., 2001). CXCL13 interacts with the CXCR5 receptor on B cells recruiting these lymphocytes into the lymphoid follicle (Ansel et al., 2000). Lymphotoxin- $\alpha 1 \beta 2$ (LT- $\alpha 1 \beta 2)$, produced by stromal cells, plays a crucial role in the early organization of the spleen (Fu and Chaplin, 1999; Mebius and Kraal, 2005). CCL21 is involved in the recruitment and retention of $\mathrm{T}$ lymphocytes in the PALS (Förster et al., 1999; Gunn et al., 1999). CXCL12 is responsible for plasma cell retention in the RP (Hargreaves et al., 2001). B-cell subtypes respond to antigens in a T-cell dependent (TD) manner. They enter the lymphoid follicle, interact with $\mathrm{CD} 4^{+} \mathrm{T}$ cells that express CD40 ligand in the germinal centers and differentiate into
IgM-, IgG- or IgA-producing plasma cells with a high-affinity to antigens. Conversely, other splenic MZ B cells may be stimulated by $\mathrm{B}$ cell-activating factor (BAFF) and a proliferation-inducing ligand (APRIL) in a T-cell independent (TI) response, which plays an important role against microbial antigens (Bernasconi et al., 2002; Tsuji et al., 2008; Cerutti et al., 2011). The two pathways (TI and TD) are complementary to provide a more specific and faster diversified immune response (Cerutti et al., 2011; Grant et al., 2012).

\section{SPLEEN IN NON-INFECTIOUS CHRONIC DISEASES}

Splenic structure and function are affected in the course of many chronic diseases. Long-lasting heart failure or impairment of liver circulation may lead to spleen congestion and stromal cell hyperplasia (Pereira et al., 2002). Hemoglobinopathies frequently course with splenic alterations (Tincani et al., 1997; O'Reilly, 1998). For example, in patients with sickle cell disease, the RP appears enlarged, with high numbers of lymphocytes and nucleated red blood cells (Szczepanek et al., 2012). Erythrocyte clumping, blood vessel obstruction and infarcts may lead to fibrosis and autosplenectomy (Al-Salem, 2011). Splenomegaly has been reported in approximately $9-41 \%$ of hepatic diseases, $4-10 \%$ of congestive or inflammatory diseases, $16-44 \%$ of lymphomas (Pozo et al., 2009) and 3\% of the cases of sarcoidosis (Judson, 2007). Lymphoid follicle hyperplasia is found in systemic lupus erythematous (SLE) and other autoimmune diseases (Auerbach et al., 2013). In SLE, polyclonal B-cell activation results in an increased number of immunoblasts, plasmacytoid lymphocytes and plasma cells in the RP (Mok and Lau, 2003). Spleen arterioles develop a hyperplasic onionskin aspect, composed of multiple layers of fibrosis and smooth muscle cell proliferation (Kitamura et al., 1985). In a series of SLE cases, extramedullary hematopoiesis was observed (Auerbach et al., 2013). In late stage diseases, lymphoid atrophy may follow (Li et al., 2013).

\section{THE SPLEEN AND INFECTION}

The spleen plays a central role in defense against circulating pathogens. Absence of the spleen predisposes to devastating consequences with the dissemination of infections by viruses, bacteria and fungi (Hansen and Singer, 2001). Changes in spleen structure are common in many systemic infections caused by viruses, bacteria and parasites (Andrade et al., 1990; Kyaw et al., 2006). Some of these infections progress with lymphoid or stromal splenic cell hyperplasia, sometimes followed by lymphoid atrophy and disorganization of spleen compartments (Abreu et al., 2001; Sonne et al., 2009; Schneider et al., 2010; Glatman Zaretsky et al., 2012; Dkhil et al., 2014; Djokic et al., 2018).

Viral infections such as Mononucleosis cause splenomegaly with mononuclear cell proliferation and atypical lymphocytes (Daneshbod and Liao, 1973; Thomas et al., 1990; Won and Ethell, 2012). In patients with AIDS, there is a progressive destruction of 


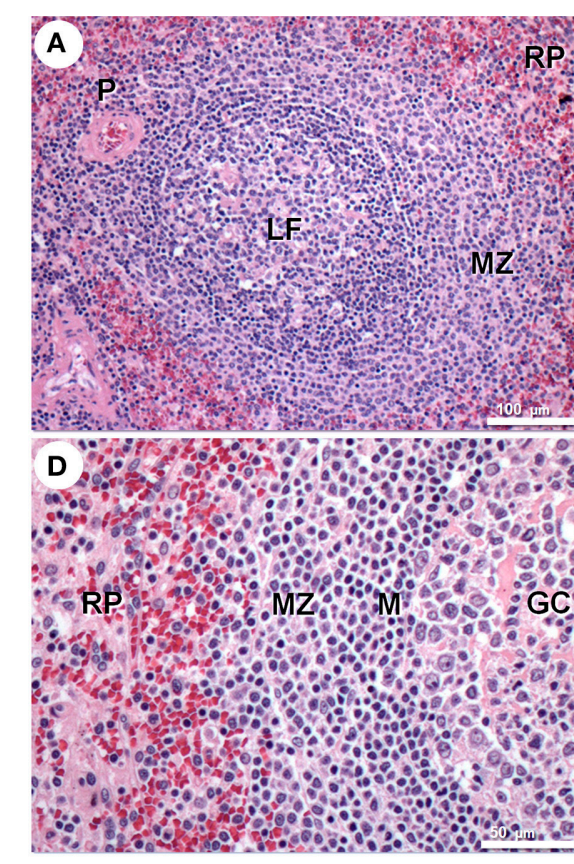

HUMAN
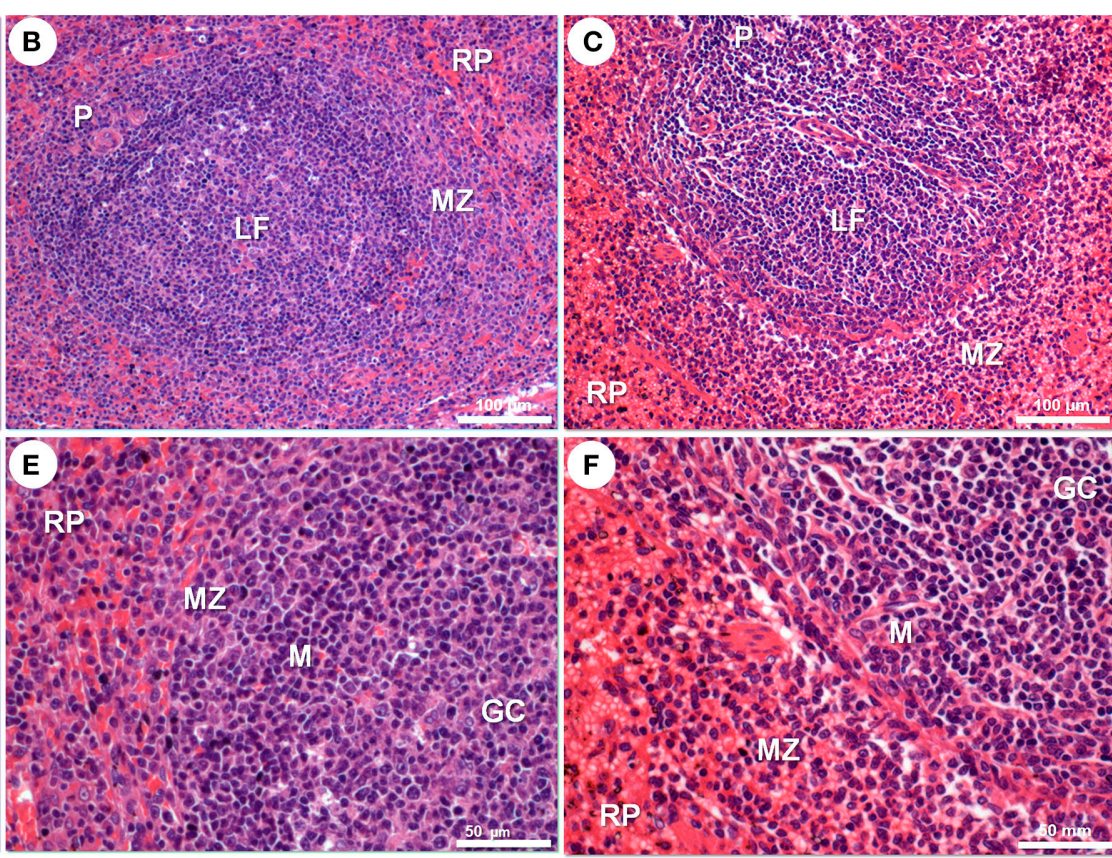

DOG

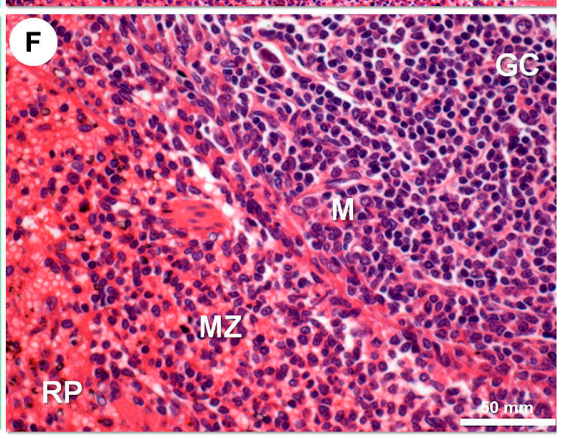

HAMSTER

FIGURE 1 | Spleen compartments in human (A,D), dog (B,E), and hamster (C,F) spleen. Spleen in all three species presents white and red pulp (RP). White pulp presents periarteriolar lymphocyte sheath $(\mathrm{P})$ and lymphoid follicles with a germinal centers $(\mathrm{GC})$ and mantle region (M) surrounded by a loosely distributed marginal zone (MZ). These spleen compartments are more clearly seen in human and dogs than in rodent spleens. Hematoxilyn-eosin staining, scale bar in (A-C) $=100 \mu m$; in (D-F) $=50 \mu \mathrm{m}$.

FDCs and concomitant germinal center loss (Fox and CottlerFox, 1992). Parvovirus infection in dogs causes splenomegaly, with lymphoid follicle hyperplasia, bleeding foci and congestion in the splenic parenchyma (Oliveira et al., 2009). In the course of bacterial infection acute splenitis, septic emboli originating, leading to infarcts and abscesses may occur (Mocchegiani and Nataloni, 2009; Wang et al., 2009). Infection with hemoparasites such as Plasmodium, Ehrlichia, Babesia, Toxoplasma gondii are all associated with splenomegaly, lymphoid tissue hyperplasia and eventually to disruption of WP structure. Schistosoma mansoni infection causes congestive splenomegaly and decreased number of lymphoid follicles and blurred marginal zones (Andrade and Bina, 1983; Brandt et al., 2005; Silva et al., 2012; Wang et al., 2015; Yan-Juan et al., 2017).

\section{STRUCTURAL DISORGANIZATION OF THE SPLEEN COMPARTMENTS}

Most of the studies concerning the morphological changes of the spleen occurring in the course of infectious and non-infectious diseases have emphasized the quantitative aspect of lymphoid or stromal hyperplasia or atrophy. Only a few authors have drawn attention to the association of the morphological changes with the redistribution of leukocyte populations resulting in the remodeling of splenic microenvironments in the course of infection and inflammation. Veress et al. (1977) first used the term disorganization to describe the changes affecting the spleen compartments in patients who died of VL. The authors considered that the change in leukocyte populations with depletion of $\mathrm{T}$ lymphocytes would lead to impairment of the cell interactions necessary to kill the parasite (Veress et al., 1977). Morrison et al. (1981b), studying Trypanosoma brucei infection, also reported a lack of reactive germinal centers and a disarrangement of lymphoid follicles in late stages of the disease. The authors considered these alterations an indication of poor function of the lymphoid system (Morrison et al., 1981b). In fact, a general description of loss of the normal architecture of the spleen is found in many studies. However, a precise definition of the histological parameters changed by infectious diseases is frequently lacking. In the studies where a more detailed description of spleen changes is presented and hyper- or hypoplastic alterations of the white and RP of the spleen is described, an MZ effacement and macrophage emigration from the MZ into the white and RP are reported (Table 1). Therefore, the term disorganization is applied to the spleen for a number of distinct changes of spleen compartments.

\section{SPLEEN DISORGANIZATION IN VL}

Although spleen changes are reported in many diseases, there are few systematic studies about the disruption of spleen compartments. We performed a systematic search in PubMed, 
TABLE 1 | Published papers mentioning spleen histological disorganization associated with parasitic infections.

\begin{tabular}{llll}
\hline References & Parasite & Host & Histological observations \\
\hline Dash et al., 2005 & Dermacentor andersoni & Mouse & $\begin{array}{l}\text { "[...] disruption of the white-pulp/red-pulp demarcations and the presence of a large number of } \\
\text { basophilic normoblasts." }\end{array}$ \\
Veress et al., 1977 & Leishmania donovani & Human & "[...]in none of the twenty 20 cases of kala-azar studied were any germinal centers seen and the
\end{tabular}

Veress et al., 1977

Leishmania donovani

Human white pulp itself was loosened and disorganized. In six out of the twenty 20 cases center necrosis was found destroying the normal architecture of the white pulp. The number of lymphocytes was invariably very low in all white pulps examined; and occasionally, the lymphocytes were virtually missing, being replaced by plasma cell and parasite-containing histiocytes."

Santana et al., $2008 \quad$ Leishmania infantum Dog

Tasca et al., 2009

Leishmania infantum

Dogs

de Lima et al., 2012

Leishmania infantum

Dog

Silva et al., 2012

Leishmania infantum

Dog

Lima et al., 2014

Leishmania infantum

Dog

Cavalcanti et al., 2015

Silva-O'Hare et al., 2016

da Silva et al., 2018

Morrison et al., $1981 a$

Trypanosoma congolense

Mouse

Leishmania infantum

Leishmania infantum

Leishmania infantum

Dog

Dog

Dog

"Degree of structural organization of the white pulp, in which the white pulp was classified as: well organized, with distinct peri-arteriolar lymphocyte sheath, germinal center, mantle zone and marginal zone; slightly disorganized, with either hyperplastic or hypoplastic changes leading to a loss in definition of any of the regions of the white pulp; moderately disorganized, when the white pulp was evident, but its regions were poorly individualized or indistinct; extensively disorganized, when the follicular structure was barely distinct from the red pulp and T-cell areas. The last two categories were frequently associated with lymphoid atrophy."

"[...] diffuse chronic inflammation with thickness of capsular and trabecular regions and [... morphological alteration of the red and white pulp by the presence of abundant macrophages filled with amastigotes, the granulomatous inflammatory reaction and hemorrhagic areas."

"(1) slightly disorganized, with either hyperplastic or hypoplastic changes leading to a loss of definition of any of the regions of the white pulp and (2) for moderately or extensively disorganized, when the white pulp regions were poorly individualized or indistinct."

The authors use a similar description as Santana et al. (2008) adding: "[...] These changes in the white pulp were associated with decreased numbers of $T$ and dendritic cells in the follicles and $B$

cells in the follicles and marginal zones."

The authors use a similar description as Santana et al. (2008) and group moderately and severely disorganized spleen into a single class type 3 spleen "[...] spleen type 3 (moderately to extensively disorganized) has white pulp evident but with poorly individualized or indistinct regions or in which the follicular structure was barely distinct from the red pulp and T-cell areas. The last category is frequently associated with lymphoid atrophy."

"[...] as described by Santana et al. (2008)."

"[...] as described by Lima et al. (2014)."

The authors use a similar description as Santana et al. (2008) and add: "The deposition of the extracellular matrix components is associated with the disorganization of the splenic white pulp; Metallopeptidase- 9 expression is higher in dogs with disorganized splenic white pulp than in dogs with organized spleen; The CD4 ${ }^{+}$cell number is lower in the disorganized spleen than in the organized spleen.

"Following the initial proliferative changes, a more protracted phase ensued during which, although the proliferative activity continued, there was a gradual disorganization of the white pulp with eventual lymphoid depletion. This was accompanied by a progressive expansion of the red pulp due to increased numbers of erythropoietic cells and to a lesser extent granulopoietic cells and macrophages. At the same time, there was a gradual decrease in the number of plasma cells found in the red pulp, although many were still present in the periarteriolar regions."

Morrison et al., 1981b Trypanosoma brucei

Dog

"Following the initial proliferative phase and prior to the death of the host during the fourth week of the infection, the spleen [...] became less reactive, and there was marked disorganization and disruption of their architecture. [...] germinal centers were reduced in number, size, and activity, had a disorganized appearance [...]."

Krucken et al., $2005 \quad$ Plasmodium chabaudi

Mouse

"[...] marginal zone macrophages (MZM) were lost and red pulp macrophages entered the white pulp."

Al-Shaebi et al., 2017

Keswani and

Bhattacharyya, 2013

Plasmodium chabaudi

Plasmodium berghei

Mouse

Mouse

"The infection causes disorganization of macrophage distribution in the spleen."

"[...] cells in the white pulp had proliferated considerably and enlarged to the limits wherein the margin between white and red pulp began to disappear and hollow spaces without cells appeared. Follicle germinal centers (GC) lost the typical architecture acquiring a disorganized aspect [...]."

Urban et al., 2005

Plasmodium falciparum

Human

" [...]The red pulp was frequently congested [...]; [...] profound depletion of B cells from the marginal zone $[. .] ;.[\ldots]$ frequency of germinal centers within lymphoid follicles was significantly reduced [...]."

Alves, 2015

Plasmodium falciparum

Monkey

"[...] spleens showed disruption of germinal center architecture with heavy B-cell activation (centroblasts). During the acute phase of infection, splenic disarray with disorganized germinal centers was observed."

da Silva et al., 2012

Schistosoma mansoni

Mouse

"[...] splenic disorganization such as a decrease in the numerical density of white pulp and, red pulp and germinal center hyperplasia."

Bauomy et al., 2014

Schistosoma mansoni
Mouse $\quad$ "...] infection induced splenomegaly and the spleen appeared with disorganized red and white pulps [...]." 
Web of Science and SCOPUS databases using the following keywords: spleen, disruption, disorganized, disorganization and white pulp. The search resulted in a total of 17 articles. Nine of these articles mentioned Leishmania infection (Table 1).

The spleen presents sequential changes during the course of VL in all susceptible hosts. The most evident change is spleen enlargement. In humans, the spleen may reach the right lower quadrant of the abdomen and gives rise to hypersplenism, a syndrome characterized by anemia, thrombocytopenia and low white blood cell counts (Dos-Santos et al., 2014). In fact, a decrease in spleen size is used as a parameter of therapeutic response in human VL (Kip et al., 2015). Leishmania-infected macrophages are observed in all spleen compartments (Andrade and Andrade, 1966). However, parasite distribution and parasite load are heterogeneous in the spleen. Culture of fine needle aspirate collected from different areas of the spleen of dogs with VL showed a variation of 3.2 and 34.7 folds in parasite load present in different regions of the upper, middle and lower third of the organ (Bagues et al., 2018). Associated granulomas, perisplenitis and progressive changes of leukocyte populations are frequently observed (Santana et al., 2008). Initially, the WP shows hyperplastic reactive lymphoid follicles and an increased number of macrophages (Veress et al., 1983; Keenan et al., 1984; Bamorovat et al., 2014). As the disease progresses, reactive lymphoid follicles are disrupted, sometimes replaced by hyaline deposits (Veress et al., 1983). The usual boundaries between the WP compartments are progressively effaced, the mantle zone progressively vanishes, and the MZ becomes less evident (Veress et al., 1977). In chronic severe forms of the disease, the spleen presents WP atrophy, to the degree that secondary lymphoid follicles are no longer found (Santana et al., 2008; Santos et al., 2016). A clear distinction between white and RP is not always feasible and numerous plasma cell aggregates replace the normal resident cell populations of the RP (Santana et al., 2008; Silva-O'Hare et al., 2016). Therefore, the increase in the size and redistribution of cell populations corresponds to an advanced state of functional disorganization of the spleen both hematologically and of defense against infections. These changes may impair the host ability to respond to infection by Leishmania and other pathogens.

To allow a better exchange of information between groups working with the structural changes of the spleen, we proposed a morphological classification of splenic WP organization based on the level of disruption of the different compartments. This classification was based on consensus analysis of the spleens of 72 dogs from an endemic area of VL performed by three pathologists. Initially, four categories were proposed: normal, slightly disorganized, moderately disorganized and intensely disorganized (Santana et al., 2008). In subsequent studies, to improve the agreement between observers, we maintained three

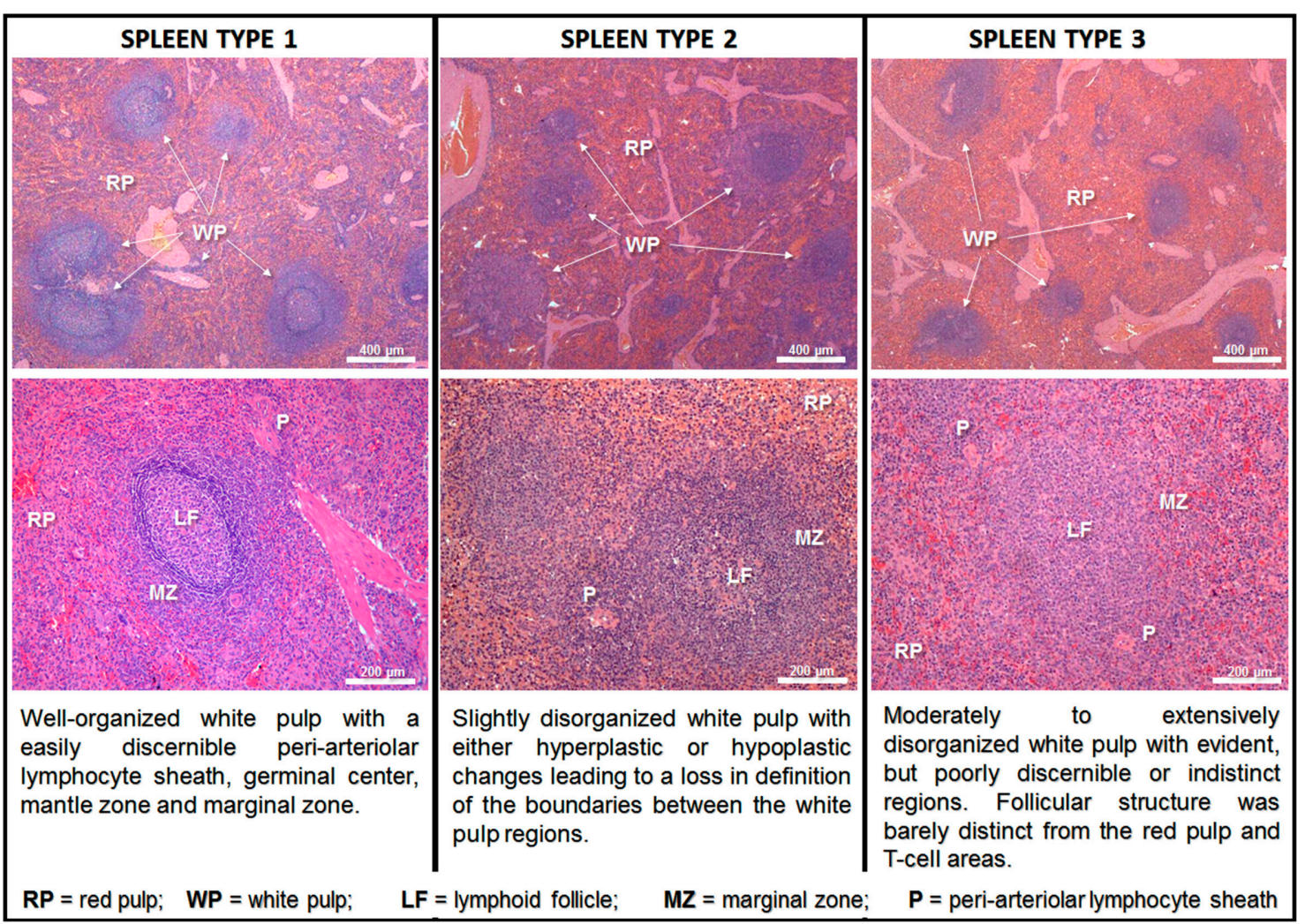

FIGURE 2 | Class of spleen disorganization according to disruption of white pulp structures. Hematoxilyn-eosin staining, scale bar in the top row = $400 \mu$ m; in the bottom row $=200 \mu \mathrm{m}$. 
categories, collapsing the moderately and intensely disorganized categories into a single category (Figure 2). Well organized spleen (spleen type 1) has a distinct periarteriolar lymphocyte sheath, lymphoid follicles and a marginal zone. Present a varied number of secondary lymphoid follicles, containing a germinal center clearly delimited by a rim of small lymphocytes (the mantle zone); slightly disorganized (spleen type 2) has either hyperplastic or hypoplastic changes blurring the boundaries between regions of the white pulp; and moderately to extensively disorganized (spleen type 3 ) the white pulp regions are poorly individualized or indistinct lymphoid follicles are barely distinct from the red pulp and T-cell areas and secondary lymphoid follicles are absent. As shown in Figure 2, the type 1 and type 3 spleens are polar categories of easily distinguished organization

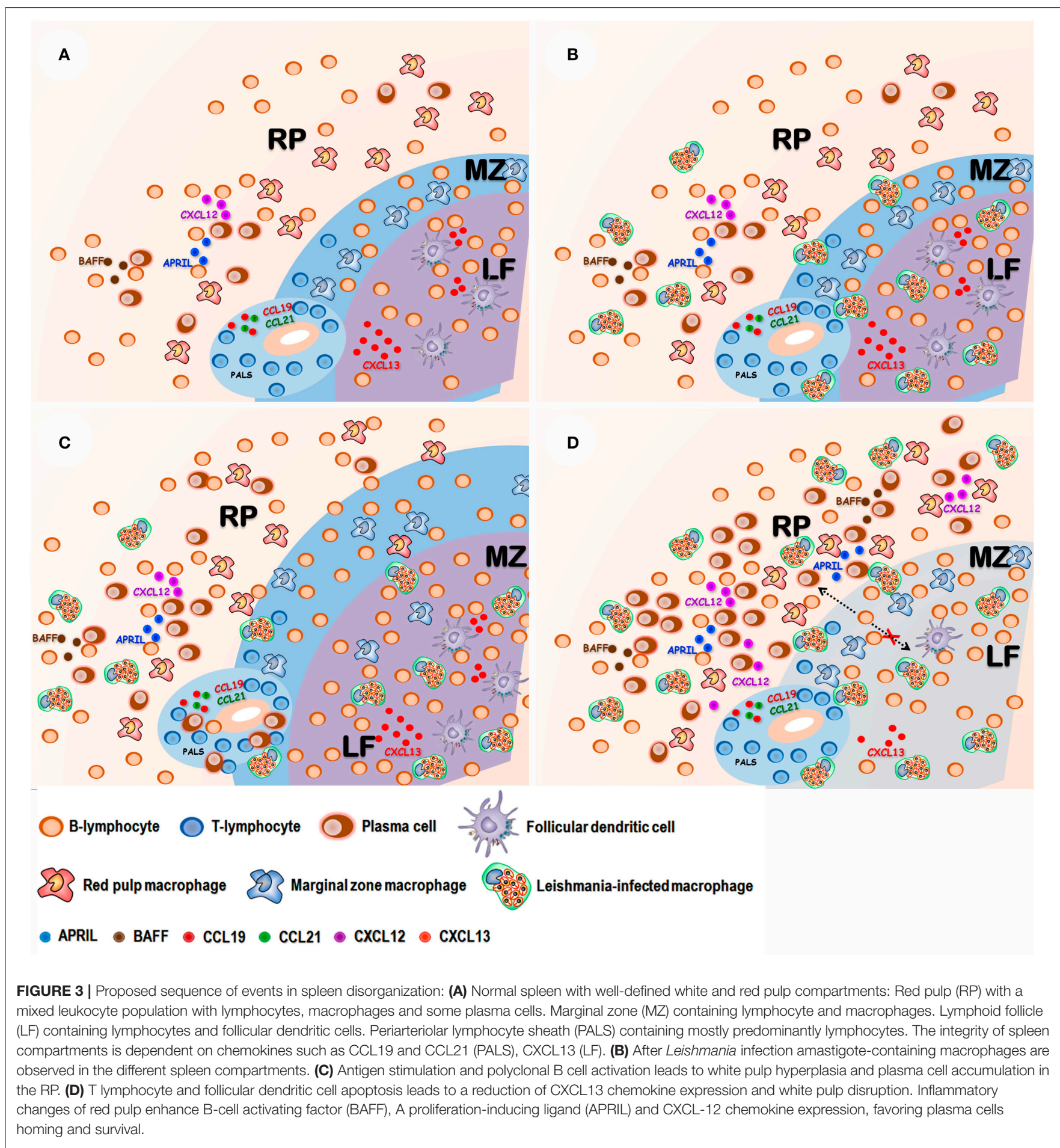


and disorganization of the WP. All the cases that do not fit into these two categories are classified as type 2 spleen (SilvaO'Hare et al., 2016). In a survey of stray dogs collected from an endemic area of VL, 23\% (48/206) of the semi-domiciled animals, most of them with Leishmania infection, presented type 3 spleens (Lima et al., 2014). Morphometric studies showed that animals with active leishmanial infection confirmed by serology or spleen culture and type 3 spleen had a smaller WP/RP proportion (6\%) than animals with type 1 spleen (13\%) (Silva et al., 2012). The decrease in WP size affects predominantly the lymphoid follicles and the MZs, which are 3.5 and 1.9 times smaller, respectively, in animals with type 3 than those of animals with type 1 spleen (Silva et al., 2012). CD79 $\alpha+$ B lymphocytes were decreased in the lymphoid follicles in the MZ and CD3 + T lymphocytes were decreased in lymphoid follicles (Silva et al., 2012). Additionally, da Silva et al. (2018) showed a decrease in number of $\mathrm{CD} 4^{+} \mathrm{T}$ lymphocytes and de Lima et al. (2012) showed increased T-cell apoptosis in the disrupted white pulp of naturally infected dogs with VL (de Lima et al., 2012; da Silva et al., 2018). These observations suggest that Tcell exhaustion may play a role in the progression of splenic alterations.

These changes in the spleen are associated with the parasite burden and with a decrease in mRNA expression of proinflammatory and anti-inflammatory cytokines related to the immune response to Leishmania such as IFN $\gamma$, IL-12, IL-6, TNF, IL-10, and TGF $\beta$ (Cavalcanti et al., 2015). Follicular dendritic cells, an important source of CXCL13, are also decreased in lymphoid follicles (Silva et al., 2012). CXCL13 is a chemokine responsible for B-cell migration into the lymphoid follicle and in lymphoid follicle maintenance (Neely and Flajnik, 2015). Smelt et al. (1997) suggested that Leishmania-infected cells present in the lymphoid follicles may correlate with follicular dendritic cell death, which may explain their reduction in late stages of the disease (Smelt et al., 1997). In fact, the gene expression for CXCL13 is significantly decreased in the spleens of dogs with active $L$. infantum infection and type 3 spleen (Silva et al., 2012). Furthermore, changes in the extracellular matrix components such as laminin and collagen, as well as an increased expression of Metallopeptidase- 9 may also participate in the process (da Silva et al., 2018).

Important changes in cell populations are also observed in splenic RP. Plasma cells progressively become the more frequent leukocyte present in this compartment (Santana et al., 2008; Silva-O'Hare et al., 2016). Plasma cells are highly specialized antibody-secreting cells derived from B lymphocytes. These cells have a complex biology arising from follicular or extrafollicular B-lymphocyte differentiation. Most plasma cells are short lived, remaining only for a few days in the WP in the spleen. Some plasmablasts migrate to the bone marrow, where a few differentiate to long-lived plasma cells (Tangye, 2011). Unfortunately, little is known about the role played by these cells in chronic inflammatory infiltrates. They are present in the spleen and are an important cell component of inflammatory infiltrates found in different organs of patients with VL (Andrade and Andrade, 1966). Spleen plasmacytosis correlates with the dysproteinemia presented by dogs with VL (Silva-O'Hare et al.,
2016). Most of the plasma cells that accumulate in the spleen in VL are IgG-producing cells. The RP plasmacytosis persists after WP disorganization and complete disruption of lymphoid follicles (Silva-O'Hare et al., 2016). This finding suggests that most of these cells continue to accumulate in the spleen either by extra follicular B-cell differentiation or by an increased life span in the RP. In fact, BAFF, APRIL and CXCL12 cell factors involved in plasma cell homing and survival are increased in the spleen of dogs with active VL and type 3 spleen (Silva-O'Hare et al., 2016). This observation suggests that inflammatory changes in the RP microenvironment may favor an increase of life span of plasma cells resulting in a shift in the composition of the leukocyte population in this spleen compartment (Figure 3).

Spleen disorganization is associated with more severe VL presentations. Dogs with active infection by L. infantum and type 3 spleen had more frequent clinical signs of disease (alopecia, anemia, conjunctivitis, dehydration, emaciation, onychogryphosis, skin erosion and ulceration), more frequently altered laboratory biochemistry and hematological tests (lower serum albumin, higher serum AST, decreased red blood cell counts and increased number of neutrophils) and more frequently negative leishmanin skin test than animals with active Leishmania infection and type 1 spleen (Lima et al., 2014; da Silva et al., 2018).

In humans who died with severe VL, Veress et al. (1977) found WP atrophy and disorganization, absence of GCcontaining lymphoid follicles, decrease in lymphocyte number and lymphocyte replacement by plasma cells (Veress et al., 1977). Recently, we comparatively studied the spleens of patients who died with VL with the spleens of patients who died of other chronic diseases and observed that patients who died of VL had more frequent WP disruption than patients without VL (unpublished data). Furthermore, patients with VL present increased levels of BAFF a cytokine involved in plasma cell differentiation and survival in the serum (Goto et al., 2014). These data suggest that the disorganization of splenic microenvironments is also relevant to human disease. In fact, sporadic reports suggest that splenectomy may contribute to the cure of patients with chronic relapsing human VL resistant to conventional drug treatment (Rees et al., 1984; Alon and Chowers, 2012).

\section{THE RELEVANCE OF SPLEEN CHANGES IN VL}

In this review, we draw attention to the marked changes in the organization of spleen compartments in severe forms of VL. These changes combine an increase in the size and altered distribution of cell components. The cell populations undergo change, and the appropriated sites of cell interactions and differentiation disappear or are substantially disrupted. Secondary lymphoid follicles, a site of development and refinement of antibody immune response, are no longer observed and MZs, homing sites for a variety of memory B cells are almost nonexistent. Since the spleen changes are usual in the 
whole course of VL, we may consider the role played by the disease in the genesis of these alterations. Furthermore, these changes in the spleen are associated with severe/terminal disease in dogs and in humans. Given the role of spleen in the protection against bloodborne pathogens the change in cell postulations and cytokine expression pattern in disorganized spleen may contribute to the progression of the disease by increasing host susceptibility to Leishmania and other pathogens. In fact, bacterial infection is among the main causes of death in patients with VL (Andrade et al., 1990; Costa et al., 2010). Therefore, the changes observed in the white and RP may impair or subvert the normal immunological functions of the spleen. A better understanding of the sequence of events and pathways involved in spleen disorganization may help to develop more sensitive tests for detecting progressive forms of $\mathrm{VL}$ and to design new approaches to the treatment of the disease.

\section{REFERENCES}

Abreu, C. B., de, Navarro, I. T., Balarin, M. R. S., Bracarense, A. P. F. R. L., Marana, E. R. M., Trapp, S. M., et al. (2001). Aspectos clínicos, patológicos e sorológicos da toxoplasmose experimental em cães jovens. Sem. Ci. Agr. 22, 123-129. doi: 10.5433/1679-0359.2001v22n2p123

Alon, D., and Chowers, M. (2012). Successful therapeutic splenectomy in an HIV patient with relapsing visceral leishmaniasis. Int. J. STD AIDS 23, 289-290. doi: 10.1258/ijsa.2009.009234

Al-Salem, A. H. (2011). Splenic complications of sickle cell anemia and the role of splenectomy. ISRN Hematol. 2011, 864257-864257. doi: 10.5402/2011/864257

Al-Shaebi, E. M., Taib, N. T., Mubaraki, M. A., Hafiz, T. A., Lokman, M. S., Al-Ghamdy, A. O., et al. (2017). Indigofera oblongifolia leaf extract regulates spleen macrophage response during Plasmodium chabaudi infection. Saudi J. Biol. Sci. 24, 1663-1666. doi: 10.1016/j.sjbs.2017.06.006

Alves, F. A. (2015). Splenic architecture disruption and parasite-induced splenocyte activation and anergy in Plasmodium falciparum-infected Saimiri sciureus monkeys. Malar J. 14:128. doi: 10.1186/s12936-015-0641-3

Andrade, T. M., Carvalho, E. M., and Rocha, H. (1990). Bacterial infections in patients with visceral leishmaniasis. J. Infect. Dis. 162, 1354-1359.

Andrade, Z. A., and Andrade, S. G. (1966). [Some new aspects of the kala-azar pathology. (Morphologic study of 13 autopsy cases)]. Rev. Inst. Med. Trop. Sao Paulo 8, 259-266.

Andrade, Z. A., and Bina, J. C. (1983). A patologia da forma hepato-esplênica da esquistossomose mansoni em sua forma avançada (estudo de 232 necrópsias completas). Pesq. Vet. Bras 78, 285-305.

Ansel, K. M., Ngo, V. N., Hyman, P. L., Luther, S. A., Förster, R., Sedgwick, J. D., et al. (2000). A chemokine-driven positive feedback loop organizes lymphoid follicles. Nature 406, 309-314. doi: 10.1038/35018581

Auerbach, A., Summers, T. A., Zhang, B., and Aguilera, N. S. (2013). Splenic manifestations of chronic autoimmune disorder: a report of five cases with histiocytic necrotizing change in four cases. Histopathology 63, 19-28. doi: $10.1111 /$ his.12143

Badaró, R., Jones, T. C., Lorenço, R., Cerf, B. J., Sampaio, D., Carvalho, E. M., et al. (1986). A prospective study of visceral leishmaniasis in an endemic area of Brazil. J. Infect. Dis. 154, 639-649.

Bagues, N. C. T., Pinheiro, C. G. M., de, Bastos, L. A., Fraga, D. B. M., Veras, P. S. T., Pontes-de-Carvalho, L. C., et al. (2018). Parasitic load and histological aspects in different regions of the spleen of dogs with visceral leishmaniasis. Comp. Immunol. Microbiol. Infect. Dis. 56, 14-19. doi: 10.1016/j.cimid.2017.11.003

Bamorovat, M., Sharifi, I., Ali Mohammadi, M., Fasihi Harandi, M., Mohebali, M., Malekpour Afshar, R., et al. (2014). Canine visceral leishmaniasis in kerman, southeast of Iran: a seroepidemiological, histopathological and molecular study. Iran J. Parasitol. 9, 342-349. Available Online at: http://ijpa.tums.ac.ir/ index.php/ijpa/article/view/393

\section{AUTHOR CONTRIBUTIONS}

WD-S, GO, MH conceived the manuscript. MH, CM, IL wrote the text. WD-S, GO revised the text. WD-S, $\mathrm{MH}$, produced the figures.

\section{FUNDING}

This work was supported by Fundação de Amparo à Pesquisa do Estado da Bahia (Fapesb. http://www.fapesb. ba.gov.br) grant no. PET0053/2013, AUXPE-CAPES-FAPESB 2072/2013/PROCESSO \#23038.006718/2013-19 and Fundação Oswaldo Cruz (Fiocruz. http://portal.fiocruz.br/pt-br-CNPq) PROEP grant 400905/2013-2. WD-S received a scholarship from CNPq. The funders had no role in the study design, data collection or analysis, decision to publish, or preparation of the manuscript.

Bauomy, A. A., Dkhil, M. A., Diab, M., Amer, O. S. O., Zrieq, R. M., and AlQuraishy, S. (2014). Response of spleen and jejunum of mice infected with Schistosoma mansoni to Mulberry treatment. Pakistan J. Zool. 46, 753-761.

Bernasconi, N. L., Traggiai, E., and Lanzavecchia, A. (2002). Maintenance of serological memory by polyclonal activation of human memory B cells. Science 298, 2199-2202. doi: 10.1126/science.1076071

Beyer, T., and Meyer-Hermann, M. (2008). Mechanisms of organogenesis of primary lymphoid follicles. Int. Immunol. 20, 615-623. doi: 10.1093/intimm/dxn020

Brandt, C. T., Leite, C. R. C., Manhaes-de-Castro, R., Brandt Filho, C., Manhaesde-Castro, F. M., and Barbosa-de-Castro, C. M. M. (2005). Evaluation of the effect of splenectomy with autologous spleen tissue implantation in some monocyte functions in children with hepatosplenic Schistosomiasis mansoni. Rev. Soc. Bras. Med. Trop. 38, 38-42. doi: 10.1590/S0037-86822005000100008

Brozman, M. (1985). Outer mantle zone of the follicle in the human spleen. Virchows Arch. A Pathol. Anat. Histopathol. 407, 107-117.

Carrión, J., Nieto, A., Iborra, S., Iniesta, V., Soto, M., Folgueira, C., et al. (2006). Immunohistological features of visceral leishmaniasis in $\mathrm{BALB} / \mathrm{c}$ mice. Parasite Immunol. 28, 173-183. doi: 10.1111/j.1365-3024.2006.00817.x

Cavalcanti, A. S., Ribeiro-Alves, M., Pereira, L. d. O. R., Mestre, G. L., Ferreira, A. B. R., Morgado, F. N., et al. (2015). parasite load induces progressive spleen architecture breakage and impairs cytokine mrna expression in Leishmania infantum-naturally infected dogs. PLoS ONE 10:e0123009. doi: 10.1371/journal.pone.0123009

Cerutti, A., Puga, I., and Cols, M. (2011). Innate control of B cell responses. Trends Immunol. 32, 202-211. doi: 10.1016/j.it.2011.02.004

Cesta, M. F. (2006). Normal structure, function, and histology of the spleen. Toxicol. Pathol. 34, 455-465. doi: 10.1080/01926230600867743

Costa, C. H. N., Werneck, G. L., Costa, D. L., Holanda, T. A., Aguiar, G. B., Carvalho, A. S., et al. (2010). Is severe visceral leishmaniasis a systemic inflammatory response syndrome? A case control study. Rev. Soc. Bras. Med. Trop. 43, 386-392. doi: 10.1590/S0037-86822010000400010

da Silva, A. M., Corrêa, C. L., Neves, R. H., and Machado-Silva, J. R. (2012). A high-fat diet associated with acute schistosomiasis mansoni causes disorganization in splenic architecture in mice. Exp. Parasitol. 132, 193-199. doi: 10.1016/j.exppara.2012.06.015

da Silva, A. V. A., Figueiredo, F. B., Menezes, R. C., Mendes-Junior, A. A., de Miranda, L. H. M., Cupolillo, E., et al. (2018). Morphophysiological changes in the splenic extracellular matrix of Leishmania infantum-naturally infected dogs is associated with alterations in lymphoid niches and the $\mathrm{CD}^{+} \mathrm{T}$ cell frequency in spleens. PLoS Negl. Trop. Dis. 12:e0006445. doi: 10.1371/journal.pntd.0006445

Daneshbod, K., and Liao, K. T. (1973). Hyaline Degeneration of Splenic Follicular Arteries in Infectious Mononucleosis: Histochemical and Electron Microscopic Studie. Am. J. Clin. Pathol. 59, 473-479. doi: 10.1093/ajcp/59.4.473 
Dash, Y., Maxwell, S. S., Rajan, T. V., and Wikel, S. K. (2005). Murine extramedullary erythropoiesis induced by tick infestation. Ann. Trop. Med. Parasitol. 99, 518-531. doi: 10.1179/136485905X51319

de Lima, V. M. F., Fattori, K. R., de Souza, F., Eugênio, F. R., Santos, dos, P. S. P., Rozza, D. B., et al. (2012). Apoptosis in T lymphocytes from spleen tissue and peripheral blood of L. (L.) chagasi naturally infected dogs. Vet. Parasitol. 184, 147-153. doi: 10.1016/j.vetpar.2011.08.024

den Haann, J. M., Mebius, R. E., and Kraal, G. (2012). Stromal cells of the mouse spleen. Front. Immunol. 3:201. doi: 10.3389/fimmu.2012.00201

Djokic, V., Akoolo, L., and Parveen, N. (2018). Babesia microti infection changes host spleen architecture and is cleared by a Th1 immune response. Front. Microbiol. 9:85. doi: 10.3389/fmicb.2018.00085

Dkhil, M. A., Al-Quraishy, S., and Al-Khalifa, M. S. (2014). The Effect of Babesia divergensInfection on the Spleen of Mongolian Gerbils. BioMed. Res. Int. 2014, 1-7. doi: 10.1155/2014/483854

Dos-Santos, W. L., Pagliari, C., Santos, L. G., Almeida, V. A., e Silva, T. L. V., Coutinho, J. d. J., et al. (2014). A case of conventional treatment failure in visceral leishmaniasis: leukocyte distribution and cytokine expression in splenic compartments. BMC Infect. Dis. 14:491. doi: 10.1186/1471-2334-14-491

Ellyard, J. I., Avery, D. T., Mackay, C. R., and Tangye, S. G. (2005). Contribution of stromal cells to the migration, function and retention of plasma cells in human spleen: potential roles of CXCL12, IL-6 and CD54. Eur. J. Immunol. 35, 699-708. doi: 10.1002/eji.200425442

Förster, R., Schubel, A., Breitfeld, D., Kremmer, E., Renner-Müller, I., Wolf, E., et al. (1999). CCR7 coordinates the primary immune response by establishing functional microenvironments in secondary lymphoid organs. Cell 99, 23-33.

Fox, C. H., and Cottler-Fox, M. (1992). The pathobiology of HIV infection. Immunol. Tod. 13, 353-356. doi: 10.1016/0167-5699(92)90171-3

Fu, Y. X., and Chaplin, D. D. (1999). Development and maturation of secondary lymphoid tissues. Annu. Rev. Immunol. 17, 399-433. doi: 10.1146/annurev.immunol.17.1.399

Glatman Zaretsky, A, Silver, J. S., Siwicki, M., Durham, A., Ware, C. F., and Hunter, C. A. (2012). Infection with Toxoplasma gondii alters lymphotoxin expression associated with changes in splenic architecture. Infect. Immun. 80, 3602-3610. doi: 10.1128/IAI.00333-12

Goto, Y., Omachi, S., Sanjoba, C., and Matsumoto, Y. (2014). Elevation of serum B-cell activating factor levels during visceral leishmaniasis. Am. J. Trop. Med. Hyg. 91, 912-914. doi: 10.4269/ajtmh.14-0260

Grant, C. F., Lefevre, E. A., Carr, B. V., Prentice, H., Gubbins, S., Pollard, A. J., et al. (2012). Assessment of T-dependent and T-independent immune responses in cattle using a B cell ELISPOT assay. Vet. Res. 43:68. doi: 10.1186/1297-9716-43-68

Gunn, M. D., Kyuwa, S., Tam, C., Kakiuchi, T., Matsuzawa, A., Williams, L. T., et al. (1999). Mice lacking expression of secondary lymphoid organ chemokine have defects in lymphocyte homing and dendritic cell localization. J. Exp. Med. 189, 451-460.

Hansen, K., and Singer, D. B. (2001). Asplenic-hyposplenic overwhelming sepsis: postsplenectomy sepsis revisited. Pediatr. Dev. Pathol. 4, 105-121. doi: $10.1007 / \mathrm{s} 100240010145$

Hargreaves, D. C., Hyman, P. L., Lu, T. T., Ngo, V. N., Bidgol, A., Suzuki, G., et al. (2001). A coordinated change in chemokine responsiveness guides plasma cell movements. J. Exp. Med. 194, 45-56. doi: 10.1084/jem.194.1.45

Herwaldt, B. L. (1999). Leishmaniasis. Lancet 354, 1191-1199. doi: 10.1016/S0140-6736(98)10178-2

Judson, M. (2007). Extrapulmonary Sarcoidosis. Semin. Respir. Crit. Care Med. 28, 083-101. doi: 10.1055/s-2007-970335

Keenan, C. M., Hendricks, L. D., Lightner, L., and Johnson, A. J. (1984). Pathology. Vet. Pathol. 21, 80-86. doi: 10.1177/030098588402100114

Keswani, T., and Bhattacharyya, A. (2013). Splenocyte apoptosis in Plasmodium berghei ANKAinfection: possible role of TNF- $\alpha$ and TGF- $\beta$. Parasite Immunol. 35, 73-90. doi: 10.1111/pim.12005

Kip, A. E., Balasegaram, M., Beijnen, J. H., Schellens, J. H. M., de Vries, P. J., and Dorlo, T. P. C. (2015). Systematic review of biomarkers to monitor therapeutic response in leishmaniasis. Antimicrob. Agents Chemother. 59, 1-14. doi: 10.1128/AAC.04298-14

Kitamura, H., Ito, T., Kanisawa, M., and Kato, K. (1985). Systemic lupus erythematosus with multiple calcified fibrous nodules of the spleen. Acta Pathol. Jpn. 35, 213-226.
Kraal, G. (1992). Cells in the marginal zone of the spleen. Int. Rev. Cytol. 132, 31-74.

Krucken, J., Mehnert, L. I., Dkhil, M. A., El-Khadragy, M., Benten, W. P. M., Mossmann, H., et al. (2005). Massive destruction of malaria-parasitized red blood cells despite spleen closure. Infect. Immun. 73, 6390?6398. doi: 10.1128/IAI.73.10.6390-6398.2005

Kyaw, M. H., Holmes, E. M., Toolis, F., Wayne, B., Chalmers, J., Jones, I. G., et al. (2006). Evaluation of severe infection and survival after splenectomy. Am. J. Med. 119, 276.e1-7. doi: 10.1016/j.amjmed.2005.07.044

Li, N., Wang, J. C., Zhu, M. H., Wang, J. Y., Fu, X. L., Zhou, J. R., et al. (2013). Pathologic diagnosis of spontaneous splenic rupture in systemic lupus erythematosus. Int. J. Clin. Exp. Pathol. 6, 273-280.

Lima, I. S., Silva, J. S., Almeida, V. A., Junior, F. G. L., Souza, P. A., Larangeira, D. F., et al. (2014). Severe clinical presentation of visceral leishmaniasis in naturally infected dogs with disruption of the splenic white pulp. PLoS ONE 9:e87742. doi: 10.1371/journal.pone.0087742

Lopes-Carvalho, T., Foote, J., and Kearney, J. F. (2005). Marginal zone B cells in lymphocyte activation and regulation. Curr. Opin. Immunol. 17, 244-250. doi: 10.1016/j.coi.2005.04.009

MacLennan, I. C. (1994). Germinal centers. Annu. Rev. Immunol. 12, 117-139. doi: 10.1146/annurev.iy.12.040194.001001

Mebius, R. E., and Kraal, G. (2005). Structure and function of the spleen. Nat. Rev. Immunol. 5, 606-616. doi: 10.1038/nri1669

Ministério da Saúde do Brasil, S. S. M. (2010). Casos confirmados de Leishmaniose Visceral. Brasil, Grandes Regiões e Unidades Federadas. 1990 a 2009. Boletim epidemiológico. Brasília: Ministério da Saúde do Brasil: 1.

Mocchegiani, R., and Nataloni, M. (2009). Complications of infective endocarditis. Cardiovasc. Hematol. Disord Drug Targets 9, 240-248. doi: 10.2174/1871529X10909040240

Mok, C. C., and Lau, C. S. (2003). Pathogenesis of systemic lupus erythematosus. J. Clin. Pathol. 56, 481-490. doi: 10.1136/jcp.56.7.481

Morrison, W. I., Murray, M., and Bovell, D. L. (1981a). Response of the murine lymphoid system to a chronic infection with Trypanosoma congolense. I. The spleen. Lab. Invest. 45, 547-557.

Morrison, W. I., Murray, M., Sayer, P. D., and Preston, J. M. (1981b). The pathogenesis of experimentally induced Trypanosoma brucei infection in the dog. II. Change in the lymphoid organs. Am. J. Pathol. 102, 182-194.

Neely, H. R., and Flajnik, M. F. (2015). CXCL13 responsiveness but not CXCR5 expression by late transitional B cells initiates splenic white pulp formation. $J$. Immunol. 194, 2616-2623. doi: 10.4049/jimmunol.1401905

Oliveira, E. C., Pescador, C. A., Sonne, L., Pavarini, S. P., Santos, A. S., Corbellini, L. G., et al. (2009). Análise imuno-histoquímica de cães naturalmente infectados pelo parvovírus canino. Pesq. Vet. Bras. 29, 131-136. doi: 10.1590/S0100-736X2009000200008

O'Reilly, R. A. (1998). Splenomegaly in 2,505 patients at a large university medical center from 1913 to 1995. 1963 to 1995: 449 patients. West. J. Med. 169, 88-97.

Pereira, S. A. de L., Rodrigues, D. B. R., Castro, E. C. D. C., Reis dos, M. A., and Teixeira, V. d. P. A. (2002). Morphometric study of the spleen in chronic Chagas' disease. Am. J. Trop. Med. Hyg. 66, 401-403. doi: $10.4269 /$ ajtmh.2002.66.401

Pozo, A. L., Godfrey, E. M., and Bowles, K. M. (2009). Splenomegaly: investigation, diagnosis and management. Blood Rev. 23, 105-111. doi: 10.1016/j.blre.2008.10.001

Rees, P. H., Kager, P. A., Kyambi, J. M., Ayim, E. N., Bhatt, K. M., and Schattenkerk, J. K. (1984). Splenectomy in kala-azar. Trop. Geogr. Med. 36, 285-292.

Santana, C. C., Vassallo, J., de Freitas, L. A. R., Oliveira, G. G. S., Pontesde-Carvalho, L. C., and dos-Santos, W. L. C. (2008). Inflammation and structural changes of splenic lymphoid tissue in visceral leishmaniasis: a study on naturally infected dogs. Parasite Immunol. 30, 515-524. doi: 10.1111/j.1365-3024.2008.01051.x

Santos, S. O., Fontes, J. L. M., Laranjeira, D. F., Vassallo, J., BarrouinMelo, S. M., and dos-Santos, W. L. C. (2016). A minimally invasive approach to spleen histopathology in dogs: a new method for follow-up studies of spleen changes in the course of Leishmania infantum infection. Comp. Immunol. Microbiol. Infect. Dis. 48, 87-92. doi: 10.1016/j.cimid.2016. 08.007

Schneider, D. A., Yan, H., Bastos, R. G., Johnson, W. C., Gavin, P. R., Allen, A. J., et al. (2010). Dynamics of bovine spleen cell populations during the acute 
response to Babesia bovis infection: an immunohistological study. Parasite Immunol. 33, 34?44. doi: 10.1111/j.1365-3024.2010.01249.x

Shi, K., Hayashida, K., Kaneko, M., Hashimoto, J., Tomita, T., Lipsky, P. E., et al. (2001). Lymphoid chemokine B cell-attracting chemokine-1 (CXCL13) is expressed in germinal center of ectopic lymphoid follicles within the synovium of chronic arthritis patients. J. Immunol. 166, 650-655. doi: 10.4049/jimmunol.166.1.650

Silva, J. S., Andrade, A. C., Santana, C. C., Santos, L. Q., Oliveira, C. I., de, Veras, P. S. T., et al. (2012). Low CXCL13 expression, splenic lymphoid tissue atrophy and germinal center disruption in severe canine visceral leishmaniasis. PLoS ONE 7:e29103. doi: 10.1371/journal.pone.0029103

Silva-O'Hare, J., de Oliveira, I. S., Klevorn, T., Almeida, V. A., Oliveira, G, G. S., Atta, A. M., et al. (2016). Disruption of splenic lymphoid tissue and plasmacytosis in canine visceral leishmaniasis: changes in homing and survival of plasma cells. PLoS ONE 11:e0156733. doi: 10.1371/journal.pone.0156733

Smelt, S. C., Engwerda, C. R., McCrossen, M., and Kaye, P. M. (1997). Destruction of follicular dendritic cells during chronic visceral leishmaniasis. J. Immunol. 158, 3813-3821.

Sonne, L., Oliveira, E. C., Pescador, C. A., Santos, A. S., Pavarini, S. P., Carissimi, A. S., et al. (2009). Achados patológicos e imuno-histoquímicos em cães infectados naturalmente pelo vírus da cinomose canina. Pesq. Vet. Bras. 29, 143-149. doi: 10.1590/S0100-736X2009000200010

Steiniger, B., and Barth, P. (2000). Microanatomy and function of the spleen. Adv. Anat. Embryol. Cell Biol. 151, III-IX- 1-101. doi: 10.1007/978-3-642-57088-9

Szczepanek, S. M., McNamara, J. T., Secor, E. R., Natarajan, P., Guernsey, L. A., Miller, L. A., et al. (2012). Splenic morphological changes are accompanied by altered baseline immunity in a mouse model of sickle-cell disease. Am. J. Pathol. 181, 1725-1734. doi: 10.1016/j.ajpath.2012.07.034

Tangye, S. G. (2011). Staying alive: regulation of plasma cell survival. Trends Immunol. 32, 595-602. doi: 10.1016/j.it.2011.09.001

Tasca, K. I., Buzetti, W. A. S., Tenorio, M., d. S., Paulan, S. d. C., Lima, F. L., de Queiroz, N. M., et al. (2009). Parasitological, immunohistochemical and histopathological study for Leishmania chagasi detection in spleenic tissues of dogs with visceral leishmaniasis. Rev. Bras. Parasitol. Vet. 18, 27-33. doi: 10.4322/rbpv.01801005

Thomas, D. M., Akosa, A. B., and Lampert, I. A. (1990). Granulomatous inflammation of the spleen in infectious mononucleosis. Histopathology 17, 265-267. doi: 10.1111/j.1365-2559.1990.tb00719.x

Tincani, E., Cioni, G., D’Alimonte, P., Cristani, A., Turrini, F., Sardini, C., et al. (1997). Value of the measurement of portal flow velocity in the differential diagnosis of asymptomatic splenomegaly. Clin. Radiol. 52, 220-223.

Townson, H., Nathan, M. B., Zaim, M., Guillet, P., Manga, L., Bos, R., et al. (2005). Exploiting the potential of vector control for disease prevention. Bull. World Health Organ. 83, 942-947.

Tsuji, M., Suzuki, K., Kitamura, H., Maruya, M., Kinoshita, K., Ivanov, I. I., et al. (2008). Requirement for lymphoid tissue-inducer cells in isolated follicle formation and $\mathrm{T}$ cell-independent immunoglobulin $\mathrm{A}$ generation in the gut. Immunity 29, 261-271. doi: 10.1016/j.immuni.2008. 05.014

Urban, B. C., Hien, T. T., Day, N. P., Phu, N. H., Roberts, R., Pongponratn, E., et al. (2005). Fatal Plasmodium falciparum Malaria Causes Specific Patterns of Splenic Architectural Disorganization. Infect. Immun. 73, 1986-1994. doi: 10.1128/IAI.73.4.1986-1994.2005

Veress, B., Abdalla, R. E., and El Hassan, A. M. (1983). Visceral spreading depletion of thymus-dependent regions and amyloidosis in mice and hamsters infected intradermally with Leishmania isolated from Sudanese cutaneous leishmaniasis. Br. J. Exp. Pathol. 64, 505-514.

Veress, B., Omer, A., Satir, A. A., and Hassan, El, A. M. (1977). Morphology of the spleen and lymph nodes in fatal visceral leishmaniasis. Immunology 33, 605-610.

Wang, C. C., Lee, C. H., Chan, C. Y., and Chen, H. W. (2009). Splenic infarction and abscess complicating infective endocarditis. Am. J. Emerg. Med. 27, 1021e3. doi: 10.1016/j.ajem.2008.12.028

Wang, Y., Zhang, J., Yin, J., Shen, Y., Wang, Y., Xu, Y., et al. (2015). The formation of egg granulomas in the spleens of mice with late Schistosoma japonicum infection alters splenic morphology. Paras. Vect. 8:375. doi: 10.1186/s13071-015-0988-x

Wessling-Resnick, M. (2015). Nramp1 and Other Transporters Involved in Metal Withholding during Infection. J. Biol. Chem. 290, 18984-18990. doi: $10.1074 /$ jbc.R115.643973

Wilson, M. E., and Streit, J. A. (1996). Visceral leishmaniasis. Gastroenterol. Clin. North Am. 25, 535-551.

Won, A. C., and Ethell, A. (2012). Spontaneous splenic rupture resulted from infectious mononucleosis. Int. J. Surg. Case Reports 3, 97-99. doi: 10.1016/j.ijscr.2011.08.012

Yan-Juan, W., Yu-Juan, S., Yu-Xin, X. U., and Jian-Ping, C. (2017). [Observation on destroyed architecture of splenic lymphoid follicles in mice infected with Schistosoma japonicumby immunohistochemistry]. Zhongguo Xue Xi Chong Bing Fang Zhi Za Zhi 29, 468-470. doi: 10.16250/j.32.1374. 2017127

Conflict of Interest Statement: The authors declare that the research was conducted in the absence of any commercial or financial relationships that could be construed as a potential conflict of interest.

Copyright (c) 2018 Hermida, de Melo, Lima, Oliveira and dos-Santos. This is an open-access article distributed under the terms of the Creative Commons Attribution License (CC BY). The use, distribution or reproduction in other forums is permitted, provided the original author(s) and the copyright owner(s) are credited and that the original publication in this journal is cited, in accordance with accepted academic practice. No use, distribution or reproduction is permitted which does not comply with these terms. 